\title{
Assembly of [5]Helicene Subunits by Palladium-Catalyzed Reactions: Synthesis, Structures, Properties, and Theoretical Study of Multiple Helicenes
}

\author{
Tomoka Hosokawa, Akihiro Tsurusaki ${ }^{*}$, and Ken Kamikawa* \\ *Department of Chemistry, Graduate School of Science, Osaka Prefecture University \\ Sakai, Osaka 599-8531, Japan
}

(Received June 30, 2020; E-mail: kamikawa@c.s.osakafu-u.ac.jp, tsurusaki@c.s.osakafu-u.ac.jp)

\begin{abstract}
Helicenes, a class of non-planar polyaromatic hydrocarbons whose characteristic is helicity, are fascinating functional molecules with unique optical and electronic properties. In recent years, "multiple helicenes" having plural helicities in a single molecule have developed rapidly into an attractive research field due to their highly distorted structure, with the partially delocalized $\pi$-systems reflecting the assembly of plural helicities. In this account, we describe our recent work covering the synthesis, structures, properties, and theoretical study of multiple helicenes, DH-1, HH-2, and TH-3. Our strategy for the synthesis of multiple helicenes includes the assembly of [5]helicene subunits by palladium-catalyzed reactions.
\end{abstract}

\section{Introduction}

Nonplanar, polycyclic aromatic compounds continue to receive extensive attention from both organic and material chemists due to their interesting structures and unique physical properties. ${ }^{1}$ One member of this class, the helicenes, have screw-shaped structures caused by the intramolecular steric repulsion between terminal benzene rings. ${ }^{2}$ The smallest helicene is [5]helicene, which has configurationally stable and can be separated into enantiomerically pure forms. A lefthanded helicene is called an $(M)$-helicene, and a right-handed one a $(P)$-helicene. Their high inversion barrier to interconversion gives rise to this helical chirality without introducing any stereogenic carbon center. This handedness means that helicenes are potentially useful in organic optoelectronics owing to their unique chiroptical properties. ${ }^{3}$

Another intriguing aspect of helicenes is the deformation of benzene rings they contain. The twisting angles of $[n]$ helicenes $(n=5-7)$ are $13.7^{\circ}-15.1^{\circ},{ }^{4}$ where "the twisting angle" is defined by carbons and centroids $(\mathrm{C}(\mathrm{a})-\mathrm{C}(\mathrm{e})-\mathrm{C}(\mathrm{f})-\mathrm{C}(\mathrm{c}))$ shown in Figure $1 .^{5}$ The introduction of multiple repulsive interactions would be an attractive method to achieve these grossly twisted structures. During our initial research, the study of stable "multiple helicenes" composed of two or more helicene substructures containing a greater than [4] helicene was still in its infancy. ${ }^{6-9}$ For example, Miao and co-workers reported the synthesis of double helicene (a). ${ }^{7}$ They show that its twisting angle $\left(26.9^{\circ}\right)$ is larger than that of [5]helicene $\left(13.7^{\circ}\right){ }^{4 a}$ Hatakeyama et al. succeeded in the synthesis of phosphorus-embedded double helicene (b) with a twisting angle of $25.0^{\circ}$ as an example of multiple heterohelicene. ${ }^{8}$ Triple helicene (c) with a $D_{3}$ symmetry was synthesized early in the development of multiple helicenes by the group of Pascal Jr. ${ }^{9 a}$ The three helicene substructures in one molecule increase its twisting angle $\left(24.0^{\circ}\right)$ in comparison to those of double helicenes. Interestingly, Segawa, Itami reported quadruple helicene (d) ${ }^{10}$ in 2016, which has a grossly twisted structure. The maximum twisting angle in the central naphthalene core reaches up to $35.3^{\circ}$, which was the largest value reported at that time.

In addition to the large deformation of a constituent ben- "[n]helicene"
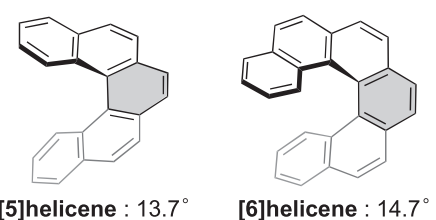

[6]helicene : $14.7^{\circ}$

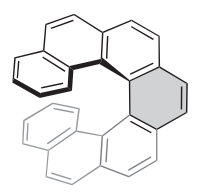

[7]helicene : $15.1^{\circ}$

"Multiple Helicene" twisting angle : $26.9^{\circ}$ a : $\mathbf{R}=\mathrm{OCH}_{3}$

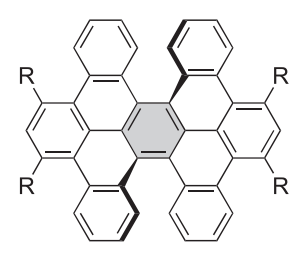

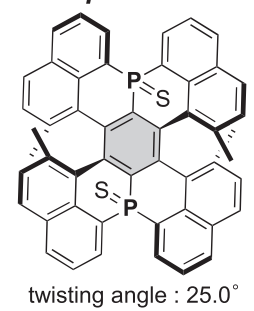

b

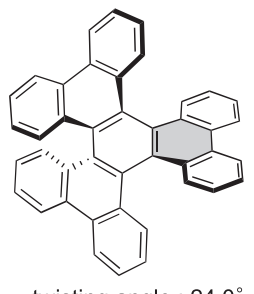

twisting angle : $24.0^{\circ}$
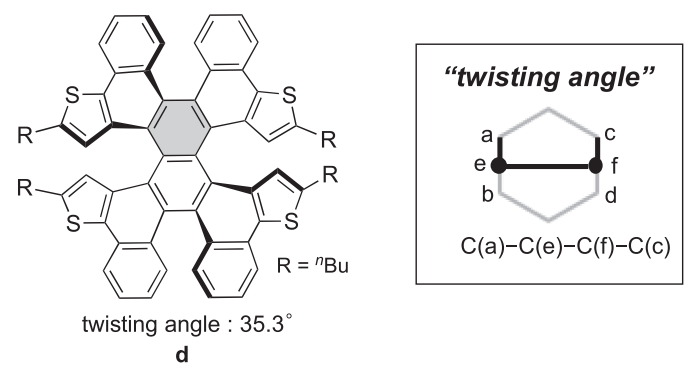

Figure 1. Some representative $[n]$ helicenes and multiple helicenes ad. The benzene ring used in the calculation of the twist angle is shown in gray. The definition of "the twisting angle" is shown in the inset.

zene ring, characteristics of multiple helicenes are their aesthetic structures, packing, and fascinating properties that are not available to compounds with a single helicity. They can also form several stereoisomers depending on how the chirality of the helicene substructures is combined. Therefore, the chemistry of multiple helicenes has developed rapidly into an attractive research field. ${ }^{11-13}$ Study of their structures and fundamental properties has the potential to shed some light on the relationship between the distortion of a benzene ring and its 
aromaticity.

Our group reported the synthesis of [5]- and [6]helicenes, as well as aza[6]helicenes, by palladium-catalyzed $\mathrm{C}-\mathrm{H}$ annulations. ${ }^{14}$ During our ongoing quest to develop the chemistry of higher multiple helicenes, we envisioned assembling [5] helicene subunits with palladium-catalyzed reactions (Figure 2). By using functionalized [5]helicenes, this enables the facile introduction of multiplicity into a molecule. In this account, we describe our recent progress on the synthesis of double helicene $\mathbf{1}(\mathbf{D H}-\mathbf{1})^{15}$ and hexapole helicenes $\mathbf{2}(\mathbf{H H}-\mathbf{2})^{16}$ as well as the enantioselective formation of triple helicenes $\mathbf{3}$ (TH-3). ${ }^{17}$ We also refer to the structures, properties, and theoretical study ${ }^{18}$ of these compounds.

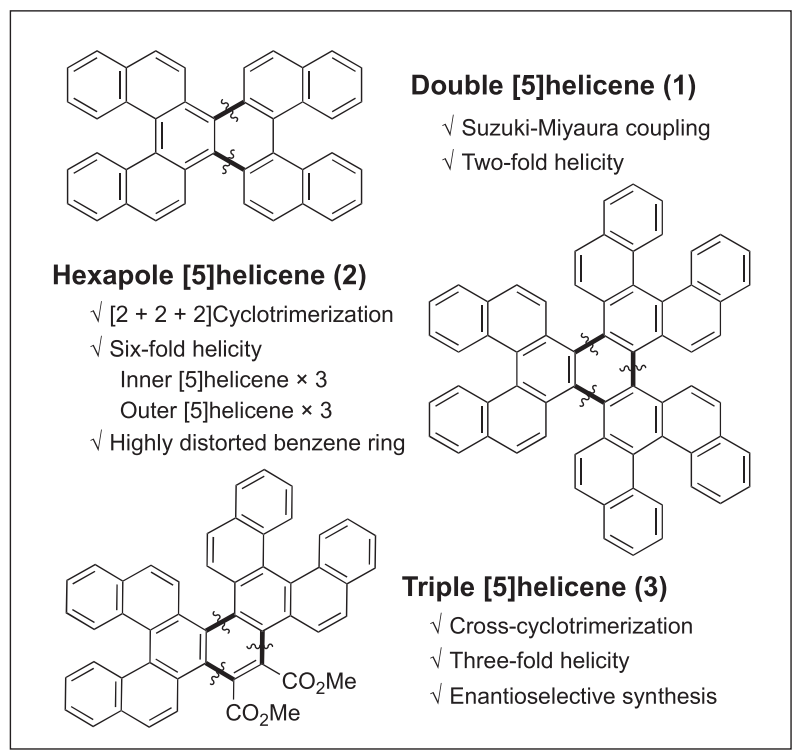

Figure 2. Our multiple helicenes 1-3 including several [5]helicene subunits.

\section{Synthesis of Multiple Helicenes 1-3 via Palladium- Catalyzed Reactions}

Double [5]helicene DH-1, in which the central benzene rings are fused back to back, was synthesized in $13 \%$ yield by a double Suzuki-Miyaura coupling reaction of 7,8-dibromo[5] helicene (4) ${ }^{19}$ with 1,1'-binaphthalene-2,2'-diyldiboronic acid (Scheme 1). ${ }^{15} \mathrm{X}$-ray crystallographic analysis (vide infra) revealed the formation of only a racemate of $(M, M)$-DH-1 among the four possible stereoisomers, while meso-DH-1 was not observed in this reaction.

Scheme 1. Synthesis of double [5]helicene (DH-1).

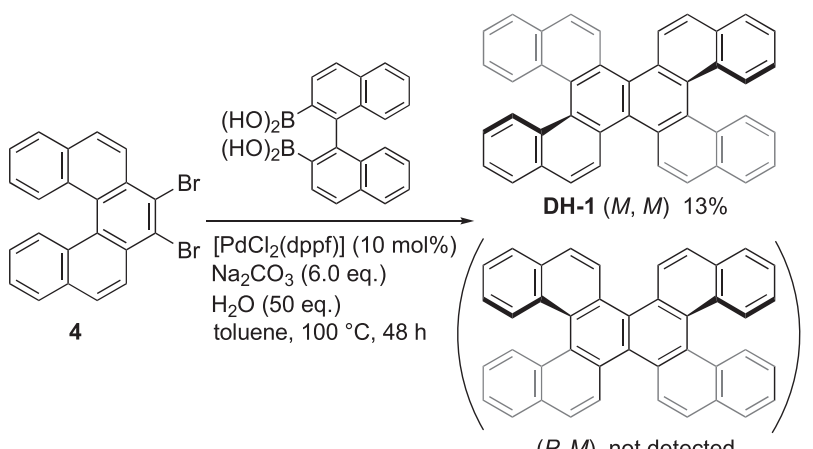

$(P, M)$ not detected
We next focused on the synthesis of hexapole [5]helicene (HH-2) as having larger multiple helicities than DH-1. HH-2 has a six-folded helical structure composed of three inner and outer [5]helicene subunits, and has 10 stereoisomers excluding enantiomers (two of $C_{1}$ symmetry, six of $C_{2}$ symmetry, and two of $D_{3}$ symmetry) owing to the six helicene substructures. Although some hexapole helicenes including the [4]helicene ${ }^{20}$ moiety had already been reported, ${ }^{21}$ multiple helicenes that contain only greater than [4]helicene subunits had not been

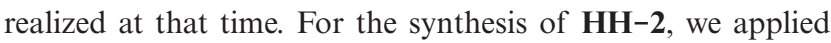
the palladium-catalyzed $[2+2+2]$ cycloaddition reaction, which had previously been used in the synthesis of $\mathbf{c}$ with three inner [5] helicene subunits in a molecule, ${ }^{9 b, 22}$ to the aryne precursor 5 . The latter was synthesized from 7,8-dibromo[5]helicene (4) in six steps, and $\mathbf{H H}-\mathbf{2 a}$ was isolated in $54 \%$ yield as a single diastereomer after the palladium-catalyzed $[2+2+2]$ cycloaddition reaction (Scheme 2a). ${ }^{16} \mathrm{X}$-ray crystallography of HH-2a revealed a $(P, M, P, P, M, P)$ configuration with $C_{2}$ symmetry, characterized by a clockwise rotation shown in Scheme 2a.

Moreover, HH-2a is quantitatively converted into the thermodynamically most stable isomer $\mathbf{H H}-\mathbf{2 b}$ with $D_{3}$ symmetry by heating in toluene solution at $100{ }^{\circ} \mathrm{C}$ for 3 hours. The enantiomers of $\mathbf{H H}-\mathbf{2 b}$ could be separated by CHIRALPAC IB, and the specific optical rotation $\left(\alpha_{D}{ }^{22}\right)$ of the faster eluting peak was determined to be $-340^{\circ}\left(c 0.10, \mathrm{CHCl}_{3}\right)$. Independently, Coquerel, Gingras, and co-workers reported the synthesis of $\mathbf{H H}-\mathbf{2}$ at around the same time, which they prepared by the Yamamoto-type $\mathrm{Ni}$-mediated coupling reaction of $\mathbf{4}$ (Scheme 2b). ${ }^{23}$ The requirement for high temperature in this reaction prohibits the isolation of HH-2a. Furthermore, Godlewski, Peña, and co-workers reported the synthesis of $\mathrm{Y}^{-}$ shaped nanographene with 22 benzene rings by on-surface $\mathrm{Au}$-promoted cyclodehydrogenation of $\mathbf{H H}-\mathbf{2}{ }^{24}$

Scheme 2. Synthesis of hexapole [5]helicene (HH-2).

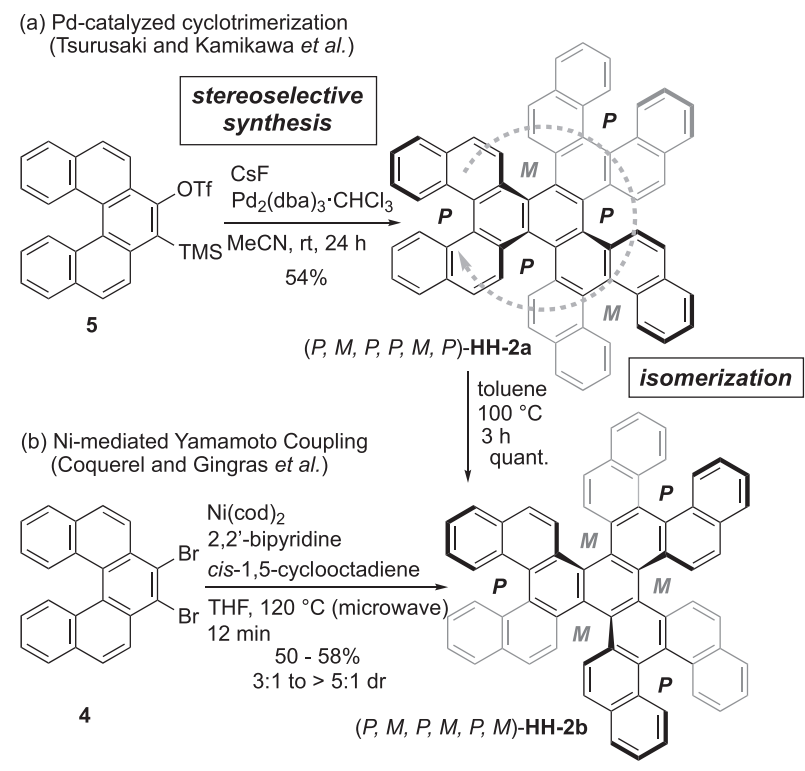

The [5]helicenyl aryne precursor 5 was also useful for palladium-catalyzed cross-cyclotrimerization with an alkyne. ${ }^{22,25}$ Especially, the possibility of using a phosphine ligand in the cross-cyclotrimerization has the potential to enable enantioselective synthesis of multiple helicenes. Achieving asymmetric synthesis is extremely important, since most enantiomerically 
pure helicenes of higher multiplicity have had to be obtained by separation of their racemic mixtures by high performance liquid chromatography (HPLC) techniques using a chiral column. Only a few examples of the asymmetric synthesis of multiple helicenes are known, such as that of S-shaped double helicenes reported by Tanaka and co-workers via the $\mathrm{Au}$-catalyzed sequential intramolecular hydroarylation of alkynes, as well as the $\mathrm{Rh}$-catalyzed intramolecular $[2+2+2]$ cycloaddition. $^{26}$

We initially examined the palladium-catalyzed crosscyclotrimerization itself (Table 1). ${ }^{17}$ When the reaction was carried out at room temperature by using 1.4 equivalent of dimethyl acetylenedicarboxylate (DMAD) 6 as the alkyne, $\mathrm{Pd}\left(\mathrm{PPh}_{3}\right)_{4}$ as palladium(0) source, and 4.0 equivalent of $\mathrm{CsF}$, the desired TH-3 was obtained in $48 \%$ yield (entry 1 ). However, HH-2a was also obtained in $32 \%$ yield. When 2.5 equivalent of $\mathbf{6}$ was used, the yield of $\mathbf{T H}-\mathbf{3}$ increased to $63 \%$ (entry 2), but $\mathbf{H H}-\mathbf{2 a}$ was still formed. Although the yield decreased to $46 \%$ at $0{ }^{\circ} \mathrm{C}$ (entry 3), TH-3 was obtained as a

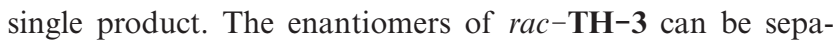
rated by CHIRALPAK IA, indicating thermal stability toward the racemization of its helicities.

Table 1. The palladium-catalyzed cross-cyclotrimerization of helicenyl aryne precursor 5 and alkyne $\mathbf{6}$.

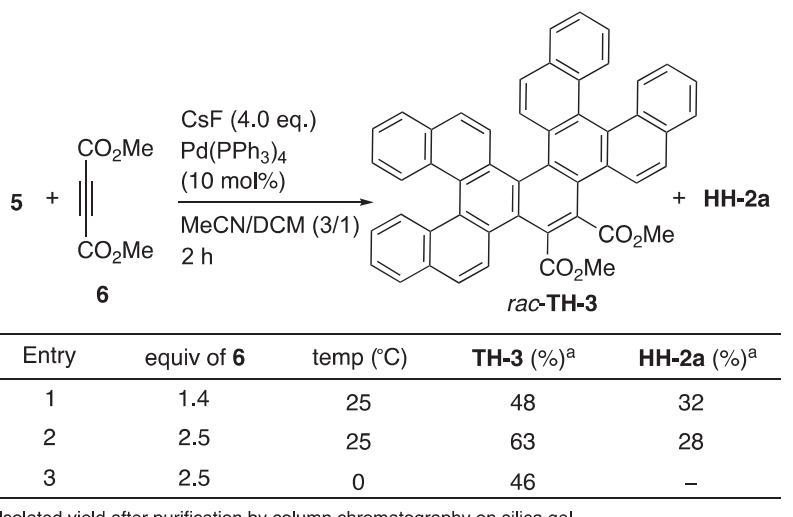

alsolated yield after purification by column chromatography on silica gel.

Subsequently, we examined the enantioselective crosstrimerization using different kinds of chiral ligands (Table 2). The reaction did not proceed when $(R)$-BINAP or $(R)-(S)-$ PPFA was used as a chiral ligand (entries 1-3), and only racTH-3 was obtained in low yields with $(R)$-Monophos or $(R)-$ KenPhos (entries 4 and 5). To our delight, $(S)$-QUINAP afforded the desired TH-3 in 49\% yield with 98:2 e.r. (entry 6). When the reaction temperature was decreased to $-20{ }^{\circ} \mathrm{C}$, the yield decreased to $38 \%$ without affecting the enantioselectivity (entry 7).

\section{Structures}

All compounds isolated were fully characterized by X-ray crystallographic analysis. The stereochemistry of $\mathbf{D H}-\mathbf{1}$ was determined to be $(M, M)$ for its [5]helicenyl moieties, and $(P$, $P$ ) for the central [4]helicenyl moieties (Figure 3). The dihedral angles between the two terminal benzene rings of helicene subunits are $53.3^{\circ}$ and $59.3^{\circ}$, which are larger than that of [5] helicene $\left(51.3^{\circ}\right)$ (Figure 3a and 3c)..$^{4 a}$ Moreover, the twisting angles in the central naphthalene core are $29.2^{\circ}$ and $29.9^{\circ}$, which are also larger than that of [5]helicene $\left(13.7^{\circ}\right)$. These results suggest that the twisting of the benzene ring is enhanced by having two helicene subunits back to back in a molecule.
Table 2. Enantioselective synthesis of $\mathbf{T H}-\mathbf{3}$. $^{\mathrm{a}}$

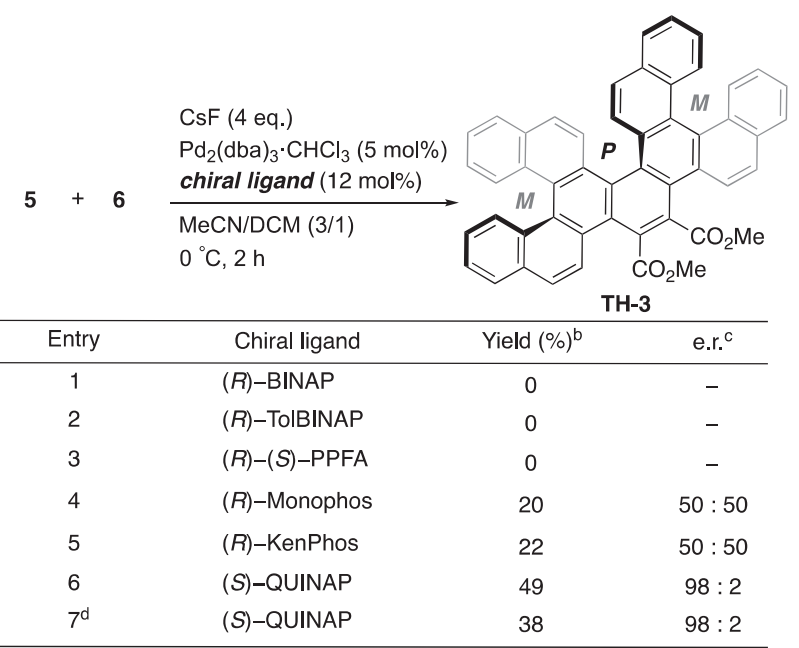

The reaction was carried out in MeCN/DCM $(3 / 1, \mathrm{v} / \mathrm{v})$ in the presence of the palladium catalyst

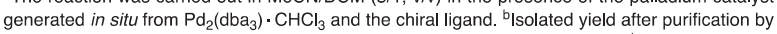
column chromatography on silica gel. ' ${ }^{D}$ Determined by chiral HPLC analysis. ${ }^{d}$ The reaction was warried out $-20^{\circ} \mathrm{C}$.

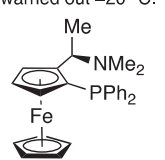

(R)-(S)-PPFA

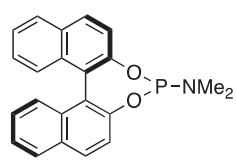

(R)-Monophos

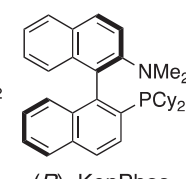

(R)-KenPhos

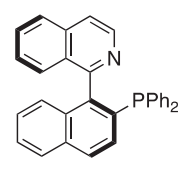

(S)-QUINAP
Interestingly, the two crystallographically independent molecules in a unit cell are dimerized through the $\pi-\pi$ interactions between the two parallel naphthalene substructures of the [5] helicene core (Figure 3b).

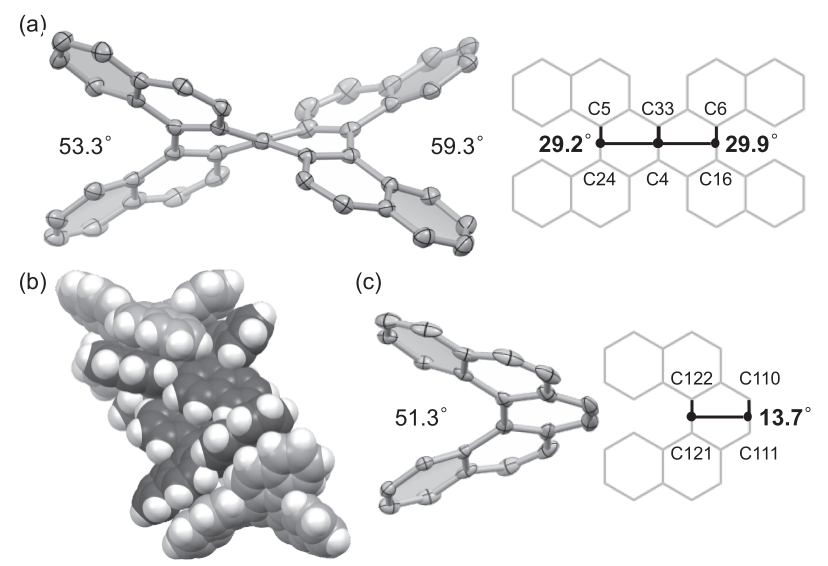

Figure 3. X-ray structure of (a) DH-1, its dihedral angles, twisting angles, and (b) packing structure. (c) X-ray structure of [5] helicene. $^{\text {4a }}$

The molecular structures of $\mathbf{H H - 2 a}$ and $\mathbf{H H}-\mathbf{2 b}$ are shown in Figure 4. Crystallography revealed that $\mathbf{H H - 2 a}$ has a highly deformed saddle-shaped structure, and a $(P, M, P, P, M, P)$ configuration with $C_{2}$ symmetry. In contrast, $\mathbf{H H}-\mathbf{2 b}$ has a propeller structure, and its stereochemistry is $(P, M, P, M, P$, $M$ ) configuration with $D_{3}$ symmetry. In HH-2a, $P$ helicities have slightly smaller dihedral angles $\left(48.1-51.4^{\circ}\right)$ compared to those of $M$ helicities $\left(55.5-56.0^{\circ}\right)$. On the other hand, the dihedral angles of the inner helicity $\left(70.3-71.4^{\circ}\right)$ in $\mathbf{H H}-\mathbf{2 b}$ are substantially larger than those of the outer one $\left(48.5-50.2^{\circ}\right)$. The most notable feature of $\mathbf{H H - 2}$ is the degree of deformation of the benzene rings, especially for the central triphenylene 
core. The largest twisting angle of the benzene ring of the central triphenylene core is found in $\mathbf{H H - 2 a}$, and is $35.7^{\circ}$, which is comparable to that of $\mathbf{d}\left(35.3^{\circ}\right) .{ }^{10}$ The twisting angles of $\mathbf{H H}-$ $\mathbf{2 b}$ are about $30.0^{\circ}$, and are larger than those of $\mathbf{c}\left(22.6-24.0^{\circ}\right)$ which has the same $D_{3}$ symmetry. ${ }^{9 \mathrm{a}}$ This result suggests that the three helicities newly introduced into the outer positions of $\mathbf{c}$ give rise to the grossly distorted structures of the central triphenylene core of $\mathbf{H H}-\mathbf{2} \mathbf{b}$.
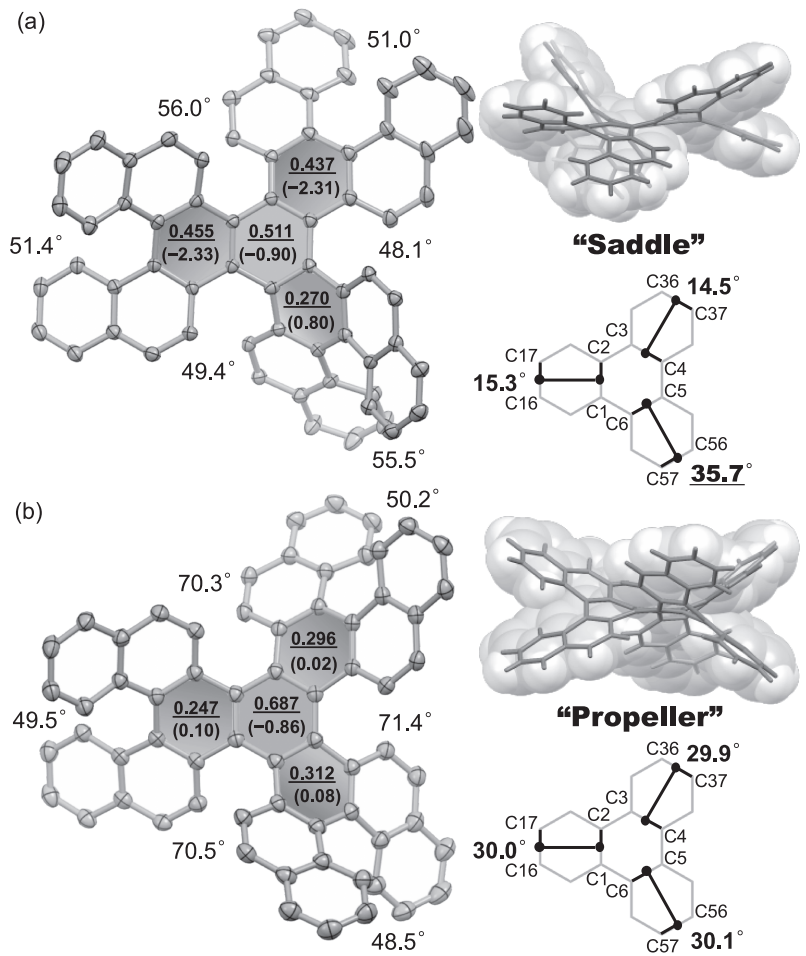

Figure 4. X-ray structure of (a) $\mathbf{H H}-\mathbf{2 a}$ and (b) $\mathbf{H H}-\mathbf{2 b}$, their dihedral angles, twisting angles, HOMA values (underline), and NICS values (in parentheses).

We also evaluated the local aromaticity of the individual rings using the harmonic oscillator model of aromaticity (HOMA), ${ }^{27}$ and the nucleus-independent chemical shift (NICS). ${ }^{28}$ The results, that the HOMA values for HH-2 decreased from the periphery to the inner benzene rings, while the NICS values increased in the same direction, show a reduction of the aromatic character of the inner rings. In particular, the HOMA and NICS values of the most distorted benzene ring in $\mathbf{H H}-\mathbf{2 a}$ are 0.270 and 0.80 , respectively, supporting a curved, twist-boat structure, while the NICS values of the central triphenylene core in $\mathbf{H H}-\mathbf{2 b}$ are $0.02-0.10$, implying low aromaticity for these rings. In addition, the HOMA value of the central benzene ring in $\mathbf{H H}-\mathbf{2 b}(0.687)$ was larger than that of $\mathbf{H H}-\mathbf{2 a}(0.511)$, which can be explained on the basis that the pitches of the outer [5]helicene in the threefold axis cancel out the twist of the benzene ring in $\mathbf{H H}-\mathbf{2 b}$.

The X-ray diffraction analysis of TH-3 obtained by the asymmetric reaction revealed the absolute configuration to be $(M, P, M)$ (Figure 5). The central [5]helicene subunit has a larger dihedral angle $\left(68.7^{\circ}\right)$ than the two outer helicene cores $\left(50.4^{\circ}\right.$ and $\left.53.0^{\circ}\right)$. The twisting angles of the central benzene ring of the outer [5] helicenes are $25.2^{\circ}$ and $27.8^{\circ}$, which are similar to those seen in c. The smaller values compared to those of $\mathbf{H H}-\mathbf{2}$ were attributed to the lesser multiplicity of the
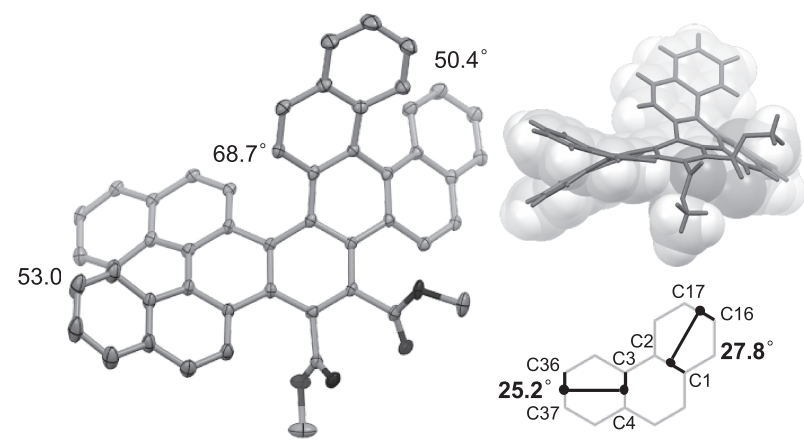

Figure 5. X-ray structure of $\mathbf{T H}-\mathbf{3}$, its dihedral angles, and twisting angles.

helicities in $\mathbf{T H}-\mathbf{3}$ than in $\mathbf{H H} \mathbf{- 2}$.

After our successful synthesis of HH-2, several groups reported larger multiple helicenes including [6]- to [9]helicenyl moieties (Figure 6). For examples, Segawa and Itami et al. synthesized quintuple helicene (e) ${ }^{29}$ in 2018 , while Wang et al. achieved the synthesis of hexapole [7]helicene (f) ${ }^{30}$ in 2018 and [9] helicene in 2019. ${ }^{31}$ Very recently, the Ravat group and the Gingras/Coquerel group independently reported the synthesis of hexapole helicene (g) including three [5]helicene and three [7]helicene moieties. ${ }^{32,33}$ These compounds also have benzene rings with large twisting angles $\left(24.2-36.9^{\circ}\right)$. Among them, the $C_{2}$ isomer of $\mathbf{g}$ has the largest twisting angle $\left(36.9^{\circ}\right)$ of any helicene yet known.

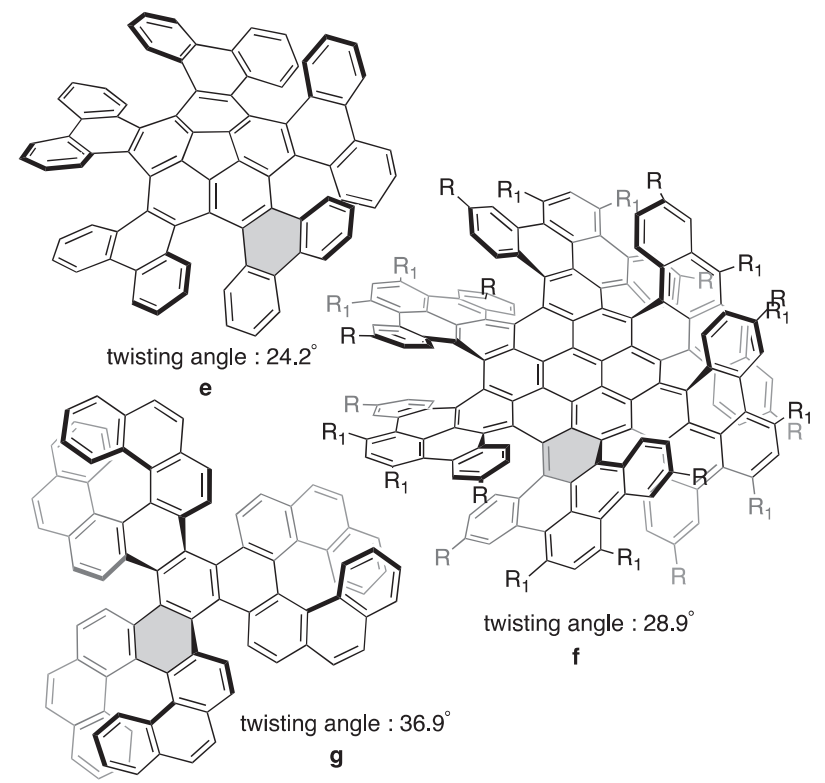

Figure 6. Recent examples of larger multiple helicenes.

\section{Photophysical Properties}

The photophysical properties (UV-vis, fluorescence, CD, and CPL) of multiple helicenes 1-3 were measured in acetone (for DH-1) and chloroform (for $\mathbf{H H}-\mathbf{2}$ and $\mathbf{T H}-\mathbf{3}$ ) (Figure 7a). The UV-vis and fluorescence spectra of $\mathbf{H H}-\mathbf{2 a}$ and $\mathbf{H H}-\mathbf{2 b}$ were almost comparable to each other. The largest absorption maxima were red-shifted in the order of DH-1 $(345 \mathrm{~nm})<$ TH-3 (353 nm) < HH-2a (393 nm) and HH-2b (393 nm) due to their extended $\pi$-conjugation. The molecular extinction coefficient $(\varepsilon)$ also becomes larger in the same order $(29,600$ for 
DH-1; 38,900 for $\mathbf{T H - 3 ; ~ 4 8 , 2 0 0 ~ f o r ~} \mathbf{H H - 2 b}$; 57,800 for HH2a). Compounds 1-3 displayed fluorescent emission in solution. The maxima were also red-shifted, again in the same order of DH-1 $(460 \mathrm{~nm})<\mathbf{T H - 3}(481 \mathrm{~nm})<\mathbf{H H}-\mathbf{2 b}$ $(513 \mathrm{~nm})$ and $\mathbf{H H}-\mathbf{2 a}(517 \mathrm{~nm})$. The lifetimes for these compounds (5.0 ns for $\mathbf{H H - 2 a}$; $5.5 \mathrm{~ns}$ for $\mathbf{H H}-\mathbf{2} \mathbf{b} ; 3.5 \mathrm{~ns}$ for $\mathbf{T H}-\mathbf{3}$ ) were fluorescent in character. The fluorescence quantum yields of $\mathbf{H H}-\mathbf{2 a}\left(\Phi_{\mathrm{f}}=0.041\right)$ and $\mathbf{H H}-\mathbf{2 b}\left(\Phi_{\mathrm{f}}=0.039\right)$ were comparable to that of [5] helicene $\left(\Phi_{\mathrm{f}}=0.04\right),{ }^{34}$ whereas that of TH-3 had a slightly larger value $\left(\Phi_{\mathrm{f}}=0.062\right)$. The increase in quantum yield for TH-3 is probably due to loss of orbital degeneracy due to introduction of the electron-withdrawing ester groups. ${ }^{35}$

The chiroptical properties of TH-3 were also investigated by measuring circular dichroism (CD) spectra and circularly polarized luminescence (CPL) in chloroform (Figure 7b). The enantiomers of $\mathbf{T H}-\mathbf{3}$ displayed mirror-image spectra with a $\Delta \varepsilon$ value in the range of $\pm 150 \mathrm{M}^{-1} \mathrm{~cm}^{-1}$. TH-3 shows CPL activity with dissymmetry factors $\left(g_{\text {lum }}\right)$ up to $-2.4 \times 10^{-3}$ at $421 \mathrm{~nm}$.
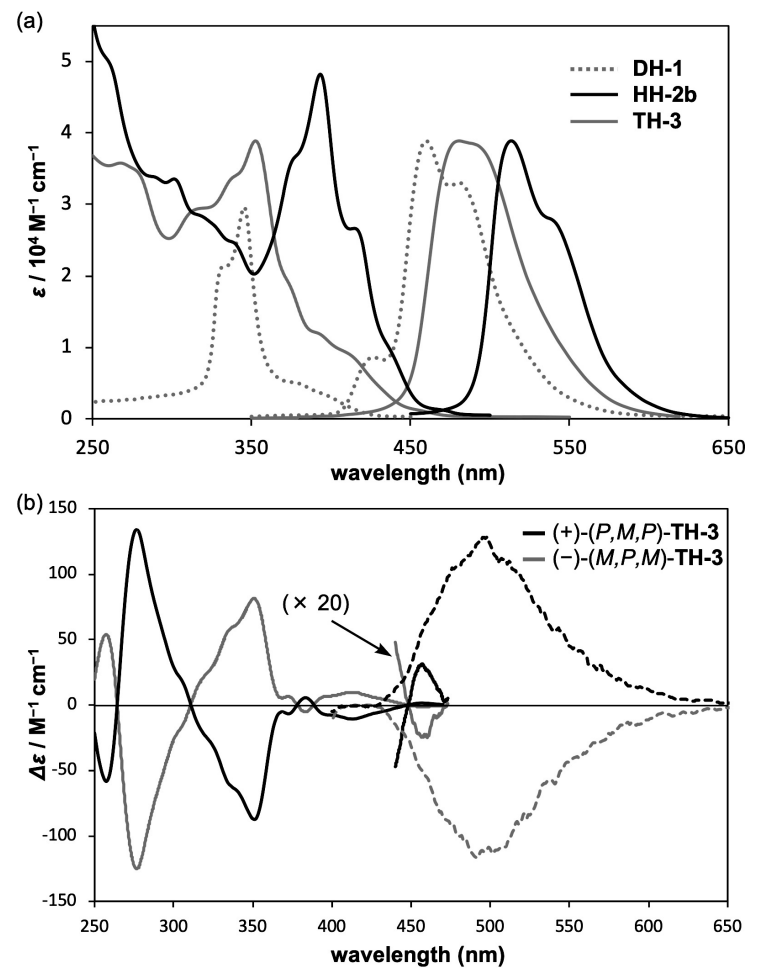

Figure 7. (a) UV-vis absorption and fluorescence spectra of 1-3. (b) $\mathrm{CD}$ (solid lines) and CPL (dashed lines) spectra of $\mathbf{T H}-\mathbf{3}$ in chloroform.

\section{Theoretical Investigations on the Formation, Isomerization and Racemization of Multiple Helicenes}

A particularly intriguing aspect of the reactions described in section 2 is the selective formation of multiple helicenes 1-3. Density functional theory (DFT) calculations were carried out to investigate the relative energy of other possible isomers, their isomerization and racemization pathways, and the possible intermediates and transition states in the $[2+2+2]$ cyclotrimerization.

We described above how the palladium-catalyzed crosscoupling reactions resulted in the selective formation of the
$(M, M)$ isomer of DH-1 (Scheme 1). DFT calculation revealed that the relative free energy of the meso- $(P, M)$ isomer is $4.8 \mathrm{kcal} \mathrm{mol}^{-1}$ higher than that of the $(M, M)$ isomer. Based on the Boltzman distribution, the probability of the meso- $(P, M)$ isomer existing is only $0.03 \%$. Furthermore, racemization from $(M, M)$ to $(P, P)$ was estimated to require $31.8 \mathrm{kcal} \mathrm{mol}^{-1}$, which is $5.4 \mathrm{kcal} \mathrm{mol}^{-1}$ higher than found for the inversion energy of [5]helicene $\left(26.4 \mathrm{kcal} \mathrm{mol}^{-1}\right.$ at the same level of calculation, while $24.1 \mathrm{kcal} \mathrm{mol}^{-1}$ at $300 \mathrm{~K}$ is the reported value ${ }^{36}$ ).

HH-2a was obtained stereoselectively in the initial reaction, and it was converted into $\mathbf{H H}-\mathbf{2 b}$ by heating in toluene solution $\left(100{ }^{\circ} \mathrm{C}, 3 \mathrm{~h}\right.$ ) (Scheme $\left.2 \mathrm{a}\right)$. DFT calculation revealed that HH-2a is the second most stable isomer of the 10 stereoisomers, and is $7.8 \mathrm{kcal} \mathrm{mol}^{-1}$ higher in energy than the most stable isomer, $\mathbf{H H}-\mathbf{2 b}$. Since, when comparing $\mathbf{H H}-\mathbf{2 a}$ and HH-2b half the stereochemistries of the [5]helicenyl moieties are opposite, one triad of $(P, M, P)$ configuration in $\mathbf{H H}-\mathbf{2 a}$ has to be converted to the $(M, P, M)$ configuration in $\mathbf{H H - 2 b}$ during the thermal isomerization. A plausible isomerization process from $\mathbf{H H}-\mathbf{2 a}$ to $\mathbf{H H}-\mathbf{2 b}$ is shown in the left side of Figure 8 (HH-2a $\rightarrow T S_{\text {ac }} \rightarrow \mathbf{H H}-2 \mathrm{c} \rightarrow \boldsymbol{T} \boldsymbol{S}_{\text {cd }} \rightarrow \mathbf{H H}-\mathbf{2 d} \rightarrow$ $\left.\boldsymbol{T} \boldsymbol{S}_{\mathrm{db}} \rightarrow \mathbf{H H}-\mathbf{2 b}\right)$. The final step $\left(\boldsymbol{T} \boldsymbol{S}_{\mathrm{db}}\right)$ is found to be the ratedetermining step in the overall inversion process, with an activation energy of $28.5 \mathrm{kcal} \mathrm{mol}^{-1}$. This is larger than that of [5] helicene $\left(24.1 \mathrm{kcal} \mathrm{mol}^{-1}\right){ }^{36}$ probably due to the additional repulsion from the neighboring [5]helicene substructures in the transition state. The racemization of $\mathbf{H H}-\mathbf{2 b}$ proceeds via three main steps as follows: (1) conversion to $\mathbf{H H - 2 a}$ in the reverse of the thermal isomerization described above, (2) interconversion among $\mathbf{H H}-\mathbf{2 c}, \mathbf{H H}-\mathbf{2 a}, \mathbf{H H}-\mathbf{2} \mathbf{a}^{*}$, and $\mathbf{H H}-\mathbf{2} \mathbf{c}^{*}$, which loses the initial chiral information, and (3) transformation of $\mathbf{H H}-\mathbf{2} \mathbf{c} *$ to $\mathbf{H H}-\mathbf{2} \mathbf{b}$ * in the same manner as occurs in thermal isomerization from $\mathbf{H H}-\mathbf{2 c}$ to $\mathbf{H H}-\mathbf{2 b}$. The racemization energy of $36.3 \mathrm{kcal} \mathrm{mol}^{-1}$ at the initial stage indicates the very great stability of the enantioisomers $\mathbf{H H}-\mathbf{2} \mathbf{b} / \mathbf{2} \mathbf{b}$ * at room temperature.

We also clarified the reason for the stereoselective formation of HH-2a via the palladium-catalyzed $[2+2+2]$ cyclotrimerization of a helicenyl aryne (Scheme $2 a) .{ }^{18}$ Interestingly, DFT calculation revealed the formation of the most stable isomers $\mathbf{H H}-\mathbf{2 b}$ requires the high free energy barrier, which is impossible to proceed at the reaction temperature. Therefore, HH-2d was formed instead of $\mathbf{H H}-\mathbf{2 b}$ and eventually isomerize to $\mathbf{H H}-\mathbf{2 a}$ as the obtained isomer.

The proposed mechanism of the palladium-catalyzed trimerization of [5]helicenyl aryne (7) is shown in Figure 9. Based on previous reports, ${ }^{37}$ the five-membered palladacycle intermediate $\mathbf{8}$ is formed from two arynes $\mathbf{7}$ and a palladium complex with ligands (L), where one or two acetonitrile molecules are coordinated to a palladium as ligands. The third aryne $\mathbf{7}$ then reacts with the intermediate $\mathbf{8}$ to give an insertion intermediate 10. The formation of Diels-Alder adduct $\mathbf{1 1}$ was also considered, but initial investigation found it to be unlikely due to the steric hindrance around the palladium atom. Finally, reductive elimination provides the $[2+2+2]$ trimerized product (HH-2).

Comparison of the relative energies of two intermediates 9a and $\mathbf{9 b}$ that might possibly lead to $\mathbf{H H}-\mathbf{2} \mathbf{a}$ showed that $\mathbf{9 a}$ is more stable than 9 b by $3.9 \mathrm{kcal} \mathrm{mol}^{-1}$ in energy (Figure 9b). Here, $\mathbf{9} \mathbf{a}$ is the adduct of $(P, M, P)-\mathbf{8}$ and $(M)-\mathbf{7}$, whereas $\mathbf{9 b}$ is the adduct of $(P, P, M)-\mathbf{8}$ and $(P)-7$. Thus, the formation of 


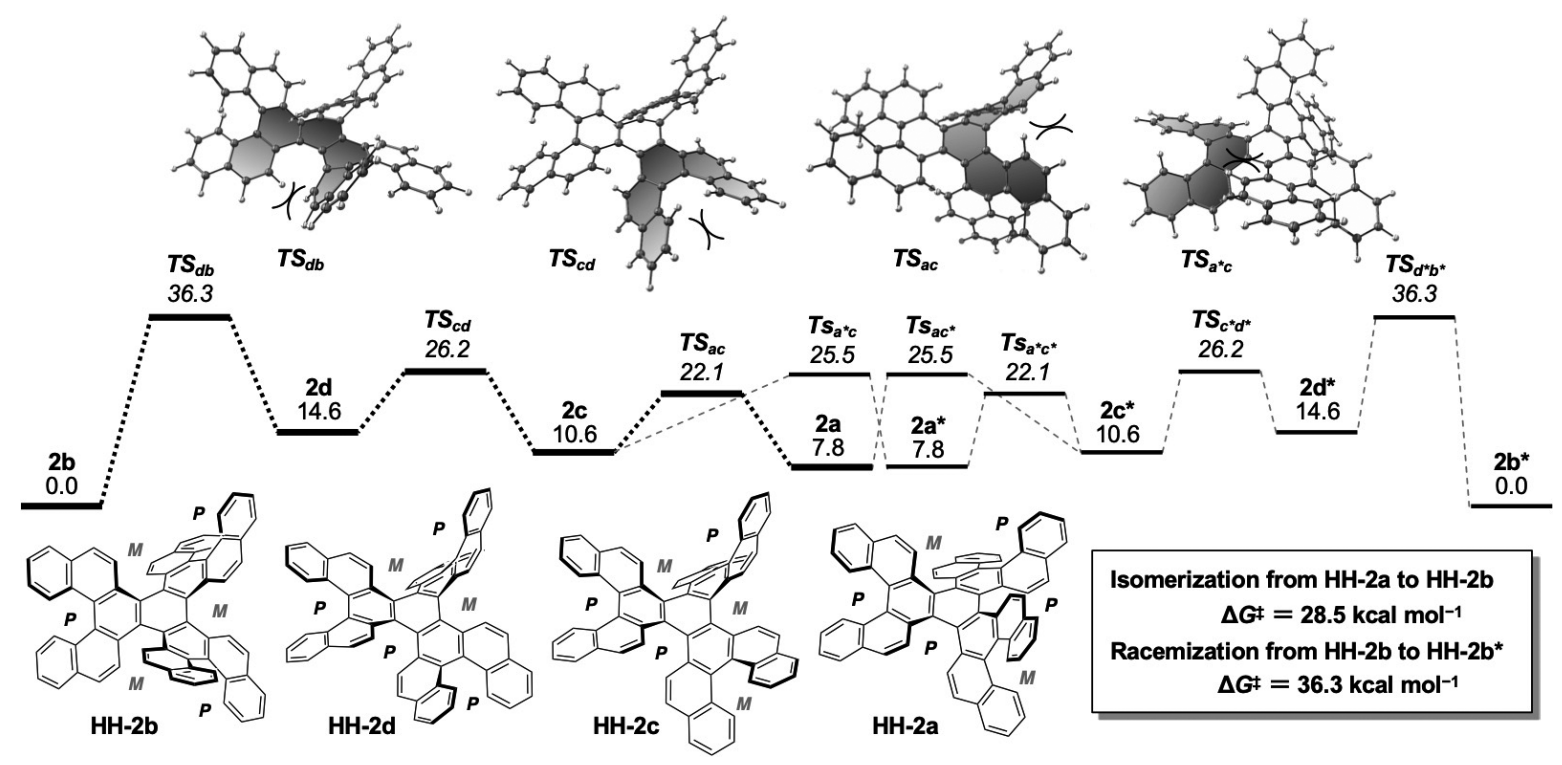

Figure 8. The isomerization process from $\mathbf{H H}-\mathbf{2 a}$ to $\mathbf{H H}-\mathbf{2 b}$ and the racemization process of $\mathbf{H H}-\mathbf{2 b}$.

(a)

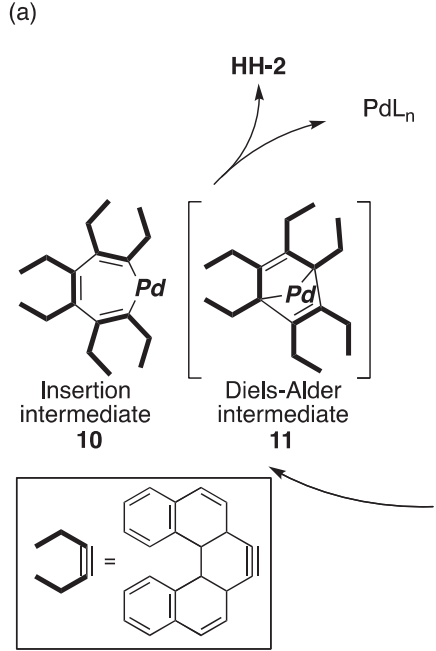

(b)

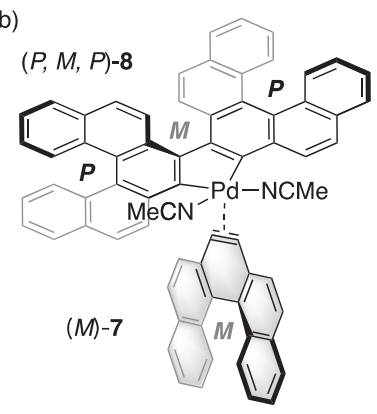

$\stackrel{9 a}{90} \mathrm{kcal} \mathrm{mol}^{-1}$
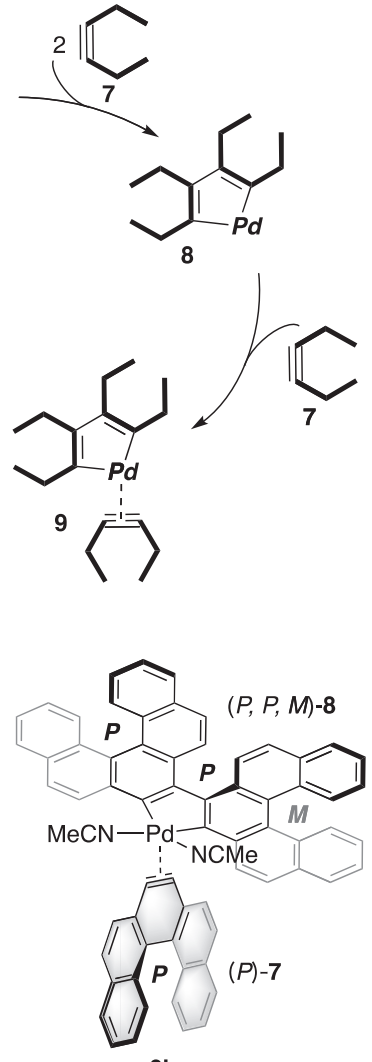

$9 \mathrm{~b}$

$3.9 \mathrm{kcal} \mathrm{mol}^{-1}$

Figure 9. (a) The reaction mechanism of the palladium-catalyzed $[2+2+2]$ cyclotrimerization of helicenyl aryne 7 . (b) Comparison in energy between intermediate $9 \mathbf{a}$ and $9 \mathbf{b}$.

HH-2a and $\mathbf{H H}-\mathbf{2 b}$ would occur from $(P, M, P)-\mathbf{8}$. The reaction of $(P, M, P)-\mathbf{8}$ with $(M)-\mathbf{7}$ proceeds smoothly to afford HH-2a with an activation energy of $18.3 \mathrm{kcal} \mathrm{mol}^{-1}$ (Figure 10, (A)). On the other hand, the addition of $(P, M, P)-\mathbf{8}$ with $(P)^{-}$ 7 gave the palladacycloheptatriene intermeadiate $\mathbf{1 0 b}$. The newly produced $(P)$-helicity in intermediate $\mathbf{1 0 b}$ should be converted to $(M)$-helicity for the formation of $\mathbf{H H}-\mathbf{2} \mathbf{b}$ that has the $(M)$-helicity at all inner positions (Figure 10, (B)). The

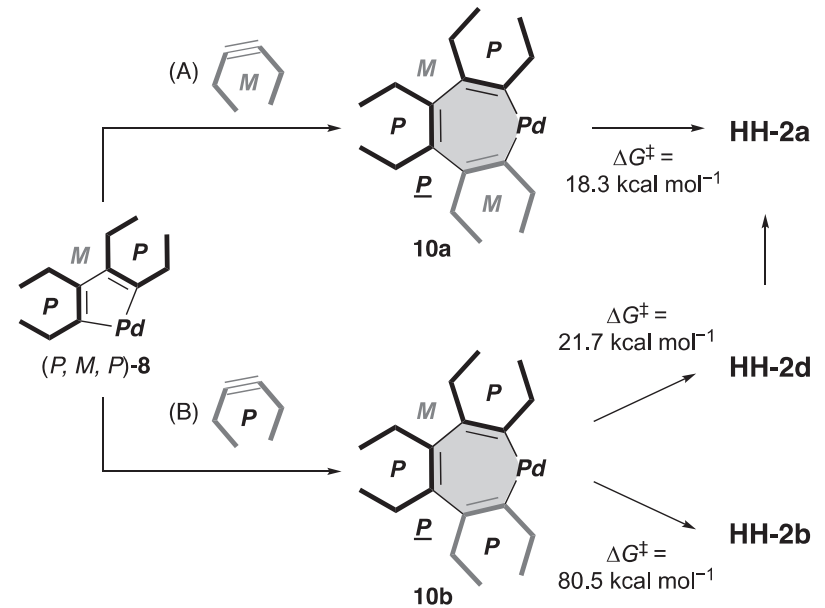

Figure 10. Two pathways for the reaction between $(P, M, P)-\mathbf{8}$ and [5]helicenyl aryne $7\left(P\right.$ or $M$ ) to yield (A) $C_{2}$ isomer $\left(\mathbf{H H}^{-}\right.$ 2a) or (B) $D_{3}$ isomer $(\mathbf{H H}-\mathbf{2 b})$.

inversion barrier was estimated to be $80.5 \mathrm{kcal} \mathrm{mol}^{-1}$, suggesting that this formation of $\mathbf{H H}-\mathbf{2 b}$ is impossible. The reductive elimination of a $\mathrm{Pd}$ fragment directly from $\mathbf{1 0 b}$ affords the isomer HH-2d, with an activation energy of $21.7 \mathrm{kcal} \mathrm{mol}^{-1}$. HH-2d thus obtained could isomerize to $\mathbf{H H}-\mathbf{2 a}$ by the thermal isomerization shown in Figure 8. Therefore, both addition of $(M)$ - and of $(P)$-helicenyl aryne to $(P, M, P)-\mathbf{8}$ afford $\mathbf{H H}-$ 2a.

The cross-cyclotrimerization of $\mathbf{5}$ with DMAD (6) to give TH-3 also follows the same reaction mechanism shown in Figure 9, except that one of the arynes is exchanged for DMAD. In the case of asymmetric reaction using a chiral $(S)$ QUINAP ligand, palladacyclopentadiene intermediates $\mathbf{1 2}$ with two arynes, or containing a diester unit $\mathbf{1 3}$, would be the possible intermediates, which would react with $\mathbf{6}$ and 7, respectively (Figure 11). Investigation of the transition states and intermediates suggested that the formation of $\mathbf{1 2}$ is preferred to $\mathbf{1 3}$ since the activation energy for the formation of $\mathbf{1 2}$ $\left(\sim 8 \mathrm{kcal} \mathrm{mol}^{-1}\right)$ is significantly lower than that of $\mathbf{1 3}(\sim 15 \mathrm{kcal}$ $\left.\mathrm{mol}^{-1}\right)$. After the formation of $\mathbf{1 2}$, inversion of the [5]helicenyl moiety of $\mathbf{1 2}$ converted the mixture of several stereoisomers to 
the most stable, $(M, P, M)$-12 with activation energies of 23-24 kcal mol ${ }^{-1}$. Next, insertion of DMAD into $(M, P, M)-$ 12 leads to the $(M, P, M)$-isomer of the palladacyclopentadiene intermediate, after which reductive elimination gives $(M$, $P, M)-\mathbf{T H}-3$ with high enantioselectivity. Based on the result of these theoretical calculations, we concluded that the asymmetric reaction shown in Table 2 proceeds via a dynamic kinetic resolution (DKR), and not a kinetic resolution (KR).

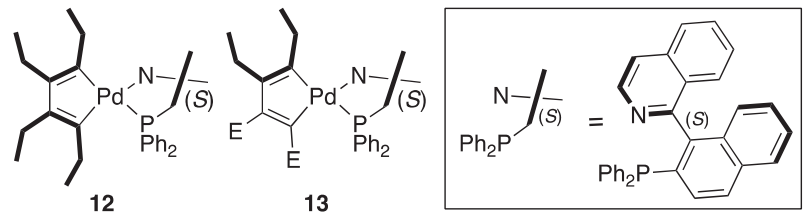

Figure 11. Possible intermediates $\mathbf{1 2}$ and $\mathbf{1 3}$ for the formation of TH-3.

\section{Conclusion}

We succeeded in the synthesis of double [5]helicene (DH1) in 2015, of hexapole [5] helicene (HH-2) in 2017, and of an enantiomerically pure triple [5]helicene (TH-3) in 2020 by using a palladium-catalyzed Suzuki-Miyaura coupling reaction, or $[2+2+2]$ cyclotrimerization reactions. Although these compounds have several stereoisomers due to the multiple helicities in the molecules, these reactions each provided a sole product. We also described how these multiple helicenes have aesthetically pleasing, but distorted structures.

The study of "multiple helicenes" has made remarkable progress in recent years. We expect that further multiple helicenes, with more extensive $\pi$-systems, as well as larger numbers of helicity and $[n]$ helicenyl moieties with $n>7$ will be prepared in the future. Furthermore, multiple helicenes have potential application in organic electron devices such as fieldeffect transistors (OFETs) and organic photovoltaic solar cells (OPVs). Some multiple helicenes were investigated to use as organic semiconductors, but their application has not been explored enough. ${ }^{7 \mathrm{~d}, 11 \mathrm{~h}, 12 \mathrm{a}, 20 \mathrm{a}, 20 \mathrm{~b}, 38}$ We believe studies of multiple helicenes will certainly be able to lead the development of new functional materials.

\section{Acknowledgements}

This work was supported by the Grant-in-Aid for Scientific Research on Innovative Areas "Precisely Designed Catalysts with Customized Scaffolding" (16H01039 and 18H04269 to K.K.) from the JSPS; a Grant-in-Aid for Scientific Research (B) (15H03780 and 18H01983 to K.K.); a Grant-inAid for Scientific Research (C) (18K05090 to A.T.); a JSPS research fellowship for young scientists (19J14567 to T.H.). The authors thank all collaborators, especially Prof. Toshio Asada, Prof. Hideki Fujiwara, Mr. Hitoshi Kashihara, Ms. Ayaka Yubuta (Osaka Prefecture University), Prof. Ikuko Miyahara (Osaka City University), Prof. Satoshi Minakata, Prof. Youhei Takeda (Osaka University), Dr. Masayuki Gon, Prof. Kazuo Tanaka, Prof. Yoshiki Chujo (Kyoto University), Dr. Tomoya Matsushima, Prof. Soichiro Watanabe, Dr. Shoko Kikkawa, and Prof. Isao Azumaya (Toho University). The partial theoretical calculations were carried out at the Research Center for Computational Science (Okazaki, Japan).

\section{References}

1) For reviews on nonplanar polyaromatic compounds, see: (a) Pascal, R. A., Jr. Chem. Rev. 2006, 106, 4809. (b) Wu, Y.-T.; Siegel, J. S. Chem. Rev. 2006, 106, 4843. (c) Rieger, R.; Müllen, K. J. Phys. Org. Chem. 2010, 23, 315. (d) Ball, M.; Zhong, Y.; Wu, Y.; Schenck, C.; Ng, F.; Steigerwald, M.; Xiao, S.; Nuckolls, C. Acc. Chem. Res. 2015, 48 , 267. (e) Segawa, Y.; Ito, H.; Itami, K. Nat. Rev. Mater. 2016, 1, 15002. (f) Segawa, Y.; Yagi, A.; Matsui, K.; Itami, K. Angew. Chem. Int. Ed. 2016, 55, 5136. (g) Pun, S. H.; Miao, Q. Acc. Chem. Res. 2018, 51, 1630. (h) Majewski, M. A.; Stępień, M. Angew. Chem. Int. Ed. 2019 58, 86. (i) Bedi, A.; Gidron, O. Acc. Chem. Res. 2019, 52, 2482. (j) Segawa, Y.; Levine, D. R.; Itami, K. Acc. Chem. Res. 2019, 52, 2760.

2) For reviews on helicenes, see: (a) Chen, C.-F.; Sheb, Y. Helicene Chemistry From Synthesis to Applications; Eds.; Springer: Berlin, 2017. (b) Shen, Y.; Chen, C.-F. Chem. Rev. 2012, 112, 1463. (c) Gingras, M. Chem. Soc. Rev. 2013, 42, 968. (d) Gingras, M.; Félix, G.; Peresutti, R. Chem. Soc. Rev. 2013, 42, 1007. (e) Gingras, M. Chem. Soc. Rev. 2013, 42, 1051. (f) Dhbaibi, K.; Favereau, L.; Crassous, J. Chem. Rev. 2019, 119, 8846. (g) Rickhaus, M.; Mayor, M.; Juríček, M. Chem. Soc. Rev. 2016, 45, 1542 .

3) (a) Kneten, N. C.; Krause, N. J.; Carmichael, T. O.; Weigang, O. E., Jr J. Am. Chem. Soc. 1962, 84, 1738. (b) Furche, F.; Ahlrichs, R.; Wachsmann, C.; Weber, E.; Sobanski, A.; Vögtle, F.; Grimme, S. J. Am. Chem. Soc. 2000, 122, 1717. (c) Tanaka, H.; Inoue, Y.; Mori, T. ChemPhoto Chem 2018, 2, 386.

4) (a) Bédard, A.-C.; Vlassova, A.; Hernandez-Perez, A. C.; Bessette, A.; Hanan, G. S.; Heuft, M. A.; Collins, S. K. Chem. Eur. J. 2013, 19, 16295. (b) Dračínský, M.; Storch, J.; Církva, V.; Císařová, I.; Sýkora, J. Phys. Chem. Chem. Phys. 2017, 19, 2900. (c) Fujino, S.; Yamaji, M.; Okamoto, H.; Mutai, T.; Yoshikawa, I.; Houjou, H.; Tani, F. Photochem. Photobiol. Sci. 2017, 16, 925.

5) Although several reported structural parameters have been used to evalute the twisting of the helicenyl moiety and the deformation of the single benzene ring, "the dihedral angle" between the two terminal benzene rings and "the twisting angle" defined in Figure 1 are used as the standard parameters in this account. When these values were not reported in the original papers, we recalculated them from information in the deposited cif files.

6) For reviews on multiple helicenes, see: (a) Kato, K.; Segawa, Y.; Itami, K. Synlett 2019, 30, 370. (b) Li, C.; Yang, Y.; Miao, Q. Chem. Asian J. 2018, 13, 884. (c) Lin, W.-B.; Li, M.; Fang, L.; Chen, C.-F. Chin. Chem. Lett. 2018, 29, 40

7) Luo, J.; Xu, X.; Mao, R.; Miao, Q. J. Am. Chem. Soc. 2012, 134, 13796.

8) Hashimoto, S.; Nakatsuka, S.; Nakamura, M.; Hatakeyama, T Angew. Chem. Int. Ed. 2014, 53, 14074.

9) (a) Barnett, L.; Ho, D. M.; Baldridge, K. K.; Pascal, R. A., Jr. J. Am. Chem. Soc. 1999, 121, 727. (b) Peña, D.; Cobas, A.; Pérez, D.; Guitián, E.; Castedo, L. Org. Lett. 2000, 2, 1629.

10) Fujikawa, T.; Segawa, Y.; Itami, K. J. Am. Chem. Soc. 2016, 138, 3587.

11) For selected examples of recent double helicenes, see: (a) Sakamaki, D.; Kumano, D.; Yashima, E.; Seki, S. Angew. Chem. Int. Ed. 2015 54, 5404. (b) Fujikawa, T.; Segawa, Y.; Itami, K. J. Am. Chem. Soc. 2015, 137, 7763. (c) Wang, X.-Y.; Wang, X.-C.; Narita, A.; Wagner, M.; Cao, X.-Y.; Feng, X.; Müllen, K. J. Am. Chem. Soc. 2016, 138, 12783. (d) Mohamed, R. K.; Mondal, S.; Guerrera, J. V.; Eaton, T. M.; Albrecht-Schmitt, T. E.; Shatruk, M.; Alabugin, I. V. Angew. Chem. Int. Ed. 2016, 55, 12054. (e) Katayama, T.; Nakatsuka, S.; Hirai, H.; Yasuda, N.; Kumar, J.; Kawai, T.; Hatakeyama, T. J. Am. Chem. Soc. 2016, 138, 5210. (f) Ferreira, M.; Naulet, G.; Gallardo, H.; Dechambenoit, P.; Bock, H.; Durola, F. Angew. Chem. Int. Ed. 2017, 56, 3379. (g) Hu, Y.; Wang, X.-Y.; Peng, P.-X.; Wang, X.-C.; Cao, X.-Y.; Feng, X.; Müllen, K.; Narita, A. Angew. Chem. Int. Ed. 2017, 56, 3374. (h) Fujikawa, T.; Mitoma, N.; Wakamiya, A.; Saeki, A.; Segawa, Y.; Itami, K. Org. Biomol. Chem. 2017, 15, 4697. (i) Oda, S.; Shimizu, T.; Katayama, T.; Yoshikawa, H.; Hatakeyama, T. Org. Lett. 2019, 21, 1770. (j) Zhou, Z.; Wang, X.-Y.; Wei, Z.; Müllen, K.; Petrukhina, M. A. Angew. Chem. Int. Ed. 2019, 58, 14969.

12) For selected examples of triple helicenes, see: (a) Meng, D.; Fu, H.; Xiao, C.; Meng, X.; Winands, T.; Ma, W.; Wei, W.; Fan, B.; Huo, L.; Doltsinis, N. L.; Li, Y.; Sun, Y.; Wang, Z. J. Am. Chem. Soc. 2016, 138, 10184. (b) Saito, H.; Uchida, A.; Watanabe, S. J. Org. Chem. 2017, 82, 5663

13) For selected examples of multiple helicenes that contains more than three helicene subunits, see: (a) Chen, Y.; Marszalek, T.; Fritz, T.; Baumgarten, M.; Wagner, M.; Pisula, W.; Chen, L.; Müllen, K. Chem. 
Commun. 2017, 53, 8474. (b) Lin, H.-A.; Kato, K.; Segawa, Y.; Scott, L. T.; Itami, K. Chem. Sci. 2019, 10, 2326. (c) Liu, G.; Koch, T.; Li, Y.; Doltsinis, N. L.; Wang, Z. Angew. Chem. Int. Ed. 2019, 58, 178. (d) Zhu, Y.; Guo, X.; Li, Y.; Wang, J. J. Am. Chem. Soc. 2019, 141, 5511.

14) (a) Kamikawa, K.; Takemoto, I.; Takemoto, S.; Matsuzaka, H. J. Org. Chem. 2007, 72, 7406. (b) Kaneko, E.; Matsumoto, Y.; Kamikawa, K. Chem. Eur. J. 2013, 19. 11837. (c) Kawashima, T.; Matsumoto, Y.; Sato, T.; Yamada, Y. M. A.; Kono, C.; Tsurusaki, A.; Kamikawa, K. Chem. Eur. J. 2020, doi: org/10.1002/chem. 202002405.

15) Kashihara, H.; Asada, T.; Kamikawa, K. Chem. Eur. J. 2015, 21, 6523

16) Hosokawa, T.; Takahashi, Y.; Matsushima, T.; Watanabe, S.; Kikkawa, S.; Azumaya, I.; Tsurusaki, A.; Kamikawa, K. J. Am. Chem. Soc. 2017, 139, 18512

17) Yubuta, A.; Hosokawa, T.; Gon, M.; Tanaka, K.; Chujo, Y.; Tsurusaki, A.; Kamikawa, K. J. Am. Chem. Soc. 2020, 142, 10025.

18) Hosokawa, T.; Asada, T.; Kamikawa, K. J. Phys. Chem. A. 2020, 124, 652.

19) Goretta, S.; Tasciotti, C.; Mathieu, S.; Smet, M.; Maes, W.; Chabre, Y. M.; Dehaen, W.; Giasson, R.; Raimundo, J.-M.; Henry, C. R.; Barth, C.; Gingras, M. Org. Lett. 2009, 11, 3846.

20) The term of "[4]helicene" is not acceptable based on the IUPAC nomenclature (see, https://goldbook.iupac.org/terms/view/H02762), but it was used here for the comparison with "[5]helicene".

21) (a) Yang, Y.; Yuan, L.; Shan, B.; Liu, Z.; Miao, Q. Chem. Eur. J. 2016, 22, 18620. (b) Xiao, S.; Myers, M.; Miao, Q.; Sanaur, S.; Pang, K.; Steigerwald, M. L.; Nuckolls, C. Angew. Chem. Int. Ed. 2005, 44, 7390. (c) Clar, E.; Stephen, J. F. Tetrahedron 1965, 21, 467.

22) Pérez, D.; Peña, D.; Guitián, E. Eur. J. Org. Chem. 2013, 5981.

23) Berezhnaia, V.; Roy, M.; Vanthuyne, N.; Villa, M.; Naubron, J.-V.; Rodriguez, J.; Coquerel, Y.; Gingras, M. J. Am. Chem. Soc. 2017, 139, 18508.

24) Zuzak, R.; Castro-Esteban, J.; Brandimarte, P.; Engelund, M.; Cobas, A.; Piatkowski, P.; Kolmer, M.; Pérez, D.; Guitián, E.; Szymonski, M.; Sánchez-Portal, D.; Godlewski, S.; Peña, D. Chem. Commun. 2018, 54, 10256.

25) Caeiro, J.; Peña, D.; Cobas, A.; Pérez, D.; Guitián, E. Adv. Synth. Catal. 2006, 348, 2466.

26) (a) Nakamura, K.; Furumi, S.; Takeuchi, M.; Shibuya, T.; Tanaka, K. J. Am. Chem. Soc. 2014, 136, 5555. (b) Satoh, M.; Shibata, Y.; Tanaka, K. Chem. Eur. J. 2018, 24, 5434. (c) Kimura, Y.; Shibata, Y.; Noguchi, K.; Tanaka, K. Eur. J. Org. Chem. 2019, 1390. (d) Kinoshita, S.; Yamano, R.; Shibata, Y.; Tanaka, Y.; Hanada, K.; Matsumoto, T.; Miyamoto, K.; Muranaka, A.; Uchiyama, M.; Tanaka, K. Angew. Chem. Int. Ed. 2020, 59, 11020.

27) (a) Kruszewski, J.; Krygowski, T. M. Tetrahedron Lett. 1972, 13, 3839. (b) Krygowski, T. M. J. Chem. Inf. Comput. Sci. 1993, 33, 70. (c) Krygowski, T. M.; Cyranśki, M. K. Chem. Rev. 2001, 101, 1385.

28) (a) Schleyer, P. v. R.; Maerker, C.; Dransfeld, A.; Jiao, H.; Hommes, N. J. R. v. E. J. Am. Chem. Soc. 1996, 118, 6317. (b) Chen, Z.; Wannere, C. S.; Corminboeuf, C.; Puchta, R.; Schleyer, P. v. R. Chem. Rev. 2005, 105, 3842 .

29) Kato, K.; Segawa, Y.; Scott, L. T.; Itami, K. Angew. Chem. Int. Ed. 2018, 57, 1337.

30) Zhu, Y.; Xia, Z.; Cai, Z.; Yuan, Z.; Jiang, N.; Li, T.; Wang, Y.; Guo, X.; Li, Z.; Ma, S.; Zhong, D.; Li, Y.; Wang, J. J. Am. Chem. Soc. 2018, $140,4222$.

31) Wang, Y.; Yin, Z.; Zhu, Y.; Gu, J.; Li, Y.; Wang, J. Angew. Chem. Int. Ed. 2019, 58, 587

32) Zhang, F.; Michail, E.; Saal, F.; Krause, A.-M.; Ravat, P. Chem. Eur. J. 2019, 25, 16241.

33) Roy, M.; Berezhnaia, V.; Villa, M.; Vanthuyne, N.; Giorgi, M.; Naubron, J.-V.; Poyer, S.; Monnier, V.; Charles, L.; Carissan, Y.; Hagebaum-Reignier, D.; Rodriguez, J.; Gingras, M.; Coquerel, Y. Angew. Chem. Int. Ed. 2020, 59, 3264.

34) Sapir, M.; Donckt, E. V. Chem. Phys. Lett. 1975, 36, 108

35) Kubo, H.; Hirose, T.; Matsuda, K. Org. Lett. 2017, 19, 1776.

36) Martin, R. H.; Marchant, M. J. Tetrahedron 1974, 30, 347.

37) For reviews on palladium-catalyzed $[2+2+2]$ cyclotrimerizations, see: (a) Domínguez G.; Pérez-Castells, J. Chem. Soc. Rev. 2011, 40, 3430. (b) Galan, B. R.; Rovis, T. Angew. Chem. Int. Ed. 2009, 48, 2830. (c) Chopade, P. R.; Louie, J. Adv. Synth. Catal. 2006, 348, 2307. (d) Kotha, S.; Brahmachary, E.; Lahiri, K. Eur. J. Org. Chem. 2005, 4741. (e) Saito, S.; Yamamoto, Y. Chem. Rev. 2000, 100, 2901. (f) Lautens, M.; Klute, W.; Tam, W. Chem. Rev. 1996, 96, 49. (g) Schore, N. E. Chem. Rev. 1988, 88, 1081.

38) (a) Shan, L.; Liu, D.; Li, H.; Xu, X.; Shan, B.; Xu, J.-B.; Miao, Q.
Adv. Mater. 2015, 27, 3418. (b) Tremblay, N. J.; Gorodetsky, A. A.; Cox, M. P.; Schiros, T.; Kim, B.; Steiner, R.; Bullard, Z.; Sattler, A. So, W.-Y.; Itoh, Y.; Toney, M. F.; Ogasawara, H.; Ramirez, A. P.; Kymissis, I.; Steigerwald, M. L.; Nuckolls, C. ChemPhysChem 2010, 11, 799. (c) Xiao, S.; Kang, S. J.; Wu, Y.; Ahn, S.; Kim, J. B.; Loo, Y.L.; Siegrist, T.; Steigerwald, M. L.; Li, H.; Nuckolls, C. Chem. Sci. 2013, 4, 2018. (d) Kang, S. J.; Ahn, S.; Kim, J. B.; Schenck, C.; Hiszpanski, A. M.; Oh, S.; Schiros, T.; Loo, Y.-L.; Nuckolls, C. J. Am. Chem. Soc. 2013, 135, 2207. (e) Zhong, Y.; Trinh, M. T.; Chen, R.; Purdum, G. E.; Khlyabich, P. P.; Sezen, M.; Oh, S.; Zhu, H.; Fowler B.; Zhang, B.; Wang, W.; Nam, C.-Y.; Sfeir, M. Y.; Black, C. T.; Steigerwald, M. L.; Loo, Y.-L.; Ng, F.; Zhu, X.-Y.; Nuckolls, C. Nat. Commun. 2015, 6, 8242 .

\section{PROFILE}

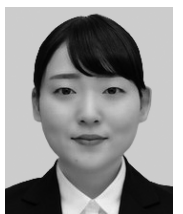

Tomoka Hosokawa graduated from Osaka Prefecture University in 2016, and received her M.Sc. in 2018 from the same university under the supervision of Prof. Ken Kamikawa. She is now a Ph.D. course student by working on multiple helicenes. She is also a JSPS Research fellow (DC2).

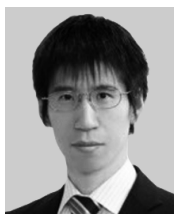

Akihiro Tsurusaki received his Ph.D. degree from Kyoto University in 2010 under the supervision of Prof. Norihiro Tokitoh. After working as a postdoctoral fellow at Kyoto University in 2010-2011, at Gunma University in 2011-2015, and at AIST in 2015-2016, he joined Osaka Prefecture University as an assistant professor in 2016. His research interests include the synthesis of ligands for catalytic reactions and $\pi$-conjugated molecules containing main group elements.

Ken Kamikawa received his Ph.D. (1998) from Osaka City University supervised by Prof. Motokazu Uemura. After working as a post-doctoral fellow (1998-1999) at Massachusetts Institute of Technology with Professor Stephen L. Buchwald, he joined the Department of Chemistry, Faculty of Integrated Arts and Sciences, Osaka Prefecture University as an assistant professor (1999). He was promoted to an associate professor in 2004 and to full professor in 2015. He was awarded the Incentive Award in Synthetic Organic Chemistry of Japan (2007). 